\title{
Evolution of aerosol optical properties from wood smoke in real atmosphere influenced by burning phase and solar radiation
}

4 Dantong $\mathrm{Liu}^{1 *}$, Siyuan $\mathrm{Li}^{1}$, Dawei $\mathrm{Hu}^{3}$, Shaofei Kong ${ }^{2 *}$, Yi Cheng ${ }^{2}$, Yangzhou Wu ${ }^{1}$,

5 Shuo Ding ${ }^{1}$, Kang $\mathrm{Hu}^{1}$, Shurui Zheng ${ }^{2}$, Qin Yan ${ }^{2}$, Huang Zheng ${ }^{2}$, Delong Zhao ${ }^{4}$, Ping

6 Tian $^{4}$, Jianhuan $\mathrm{Ye}^{5}$, Mengyu Huang ${ }^{4}$, Deping Ding ${ }^{4}$

7

8

91 Department of Atmospheric Sciences, School of Earth Sciences, Zhejiang University, 10 Hangzhou, Zhejiang, China

112 Department of Atmospheric Sciences, School of Environmental Studies, China University 12 of Geosciences, Wuhan, China

133 Centre for Atmospheric Sciences, School of Earth and Environmental Sciences, University 14 of Manchester, Manchester M13 9PL, UK

154 Beijing Weather Modification Office, China

165 School of Engineering and Applied Sciences, Harvard University, Cambridge,

17 Massachusetts, 02138, USA

18

19 Section S1.

20 Section S2.

21 Table S1.

22 Figure S1-S10. 
We examined the effects of temperature on the gas-particle partitioning of semivolatile organic species (SVOCs) in different volatility bins from 0.01 to $100 \mu \mathrm{g} \mathrm{m}^{-3}$. This volatility range is selected for biomass burning OA (BBOA) based on literature studies ${ }^{1,2}$. Particle phase fraction $\left(f_{\mathrm{p}}\right)$ was used for discussion, which can be calculated as follows:

$f_{p, i}=\frac{1}{1+C_{i}^{*} / M_{O A}}$

where, $C_{i}^{*}$ is the saturation vapor pressure of $\operatorname{SVOC} i, M_{O A}$ is the mass concentration of the absorbing organic particles, taken as $50 \mathrm{ug} \mathrm{m}^{-3}$ based on the light experiments.

Increasing temperature leads to an increase in the sub-cooled vapor pressure of SVOC, further resulting in enhanced $C^{*}$. As shown in the sensitivity analysis in Table $\mathrm{S} 1$, the extent of temperature effect varies with the volatility of SVOC. Assuming that $\log C^{*}$ changes by 0.5 by increasing temperature from $38^{\circ} \mathrm{C}$ to $50^{\circ} \mathrm{C}, f_{\mathrm{p}}$ decreases from $33 \%$ (entry \#5, Table $\mathrm{S} 1$ ) to $13 \%$ (entry \#10) for SVOC with $C^{*}$ of $100 \mu \mathrm{g} \mathrm{m}^{-3}$, this value further reduces to $5 \%$ (entry \#15) when $\log C^{*}$ is subject to a greater influence. However, little change was observed for less volatile species (e.g., $C^{*}=0.01$ to $1 \mu \mathrm{g} \mathrm{m}^{-3}$ ) by increasing temperature.

Laboratory measurements observed that increasing temperature promoted the evaporation of BBOA. However, a temperature increase from $38{ }^{\circ} \mathrm{C}$ to $50{ }^{\circ} \mathrm{C}$ decreases the particle mass fraction of BBOA by around $10-15 \%^{2,3}$, indicating that the majority of BBOA species are relatively less volatile. Therefore, the effects of temperature on OA loading in our chamber experiments are limited. We have included this information in the revised discussion.

Table S1. Effects of temperature on gas-particle partitioning of semivolatile organic species.

\begin{tabular}{|c|c|c|c|c|}
\hline$\#$ & $\mathbf{T}\left({ }^{\circ} \mathrm{C}\right)$ & $\log C^{*}$ & $C^{*}\left(\mu \mathrm{g} \mathrm{m}^{-3}\right)$ & $\begin{array}{c}f_{\mathrm{p}} \\
\left(\text { assuming } M_{O A}=50 \mu \mathrm{g} \mathrm{m}^{-3} \text { ) }\right.\end{array}$ \\
\hline 1 & 38 & -2 & $1.00 \mathrm{E}-02$ & $100 \%$ \\
\hline 2 & & -1 & $1.00 \mathrm{E}-01$ & $100 \%$ \\
\hline 3 & & 0 & $1.00 \mathrm{E}+00$ & $98 \%$ \\
\hline 4 & & 1 & $1.00 \mathrm{E}+01$ & $83 \%$ \\
\hline 5 & & 2 & $1.00 \mathrm{E}+02$ & $33 \%$ \\
\hline 6 & 50 & -1.5 & $3.16 \mathrm{E}-02$ & $100 \%$ \\
\hline 7 & & -0.5 & $3.16 \mathrm{E}-01$ & $99 \%$ \\
\hline 8 & & 0.5 & $3.16 \mathrm{E}+00$ & $94 \%$ \\
\hline 9 & & 1.5 & $3.16 \mathrm{E}+01$ & $60 \%$ \\
\hline 10 & & 2.5 & $3.16 \mathrm{E}+02$ & $13 \%$ \\
\hline 11 & 50 & -1 & $1.00 \mathrm{E}-01$ & $100 \%$ \\
\hline 12 & & 0 & $1.00 \mathrm{E}+00$ & $98 \%$ \\
\hline
\end{tabular}


13

14

15
$1.00 \mathrm{E}+01$

$83 \%$

$1.00 \mathrm{E}+02$

$1.00 \mathrm{E}+03$
$32 \%$

$5 \%$

45 
The Proton-Transfer-Reactor Time-of-Flight Mass Spectrometer (PTR-ToF-MS 8000, Ionicon Analytik GmbH Innsbruck, Austria) was deployed to quantify the volatile organic compounds (VOCs). Operating and calibration of the PTR followed the routine described previously ${ }^{4,5}$.

50 Here we used the decay of furan which was exclusively from biomass burning emission during 51 experiments, to estimate the concentration of hydroxyl radical $(\mathrm{OH} \cdot)$ in the chamber. The 52 second order rate coefficient of furan with $\mathrm{OH} \cdot, k$ (furan), is from Atkinson $1986^{6}$, using the following parameterization:

$$
k(\text { furan })=\left(1.32_{-0.24}^{+0.30}\right) \times 10^{-11} e^{(334 \pm 62) / T} \mathrm{~cm}^{3} \text { molecule }{ }^{-1} S^{-1}
$$
to calculate $k$ (furan) spanning the experimental temperature, which is $4.05 \times 10^{-11} \mathrm{~cm}^{3}$ molecule ${ }^{1} \mathrm{~s}^{-1}$ at $298 \mathrm{~K}$ and $3.71 \times 10^{-11} \mathrm{~cm}^{3}$ molecule ${ }^{-1} \mathrm{~s}^{-1}$ at $323 \mathrm{~K}$. The $k$ (furan) under chamber temperature was used. 


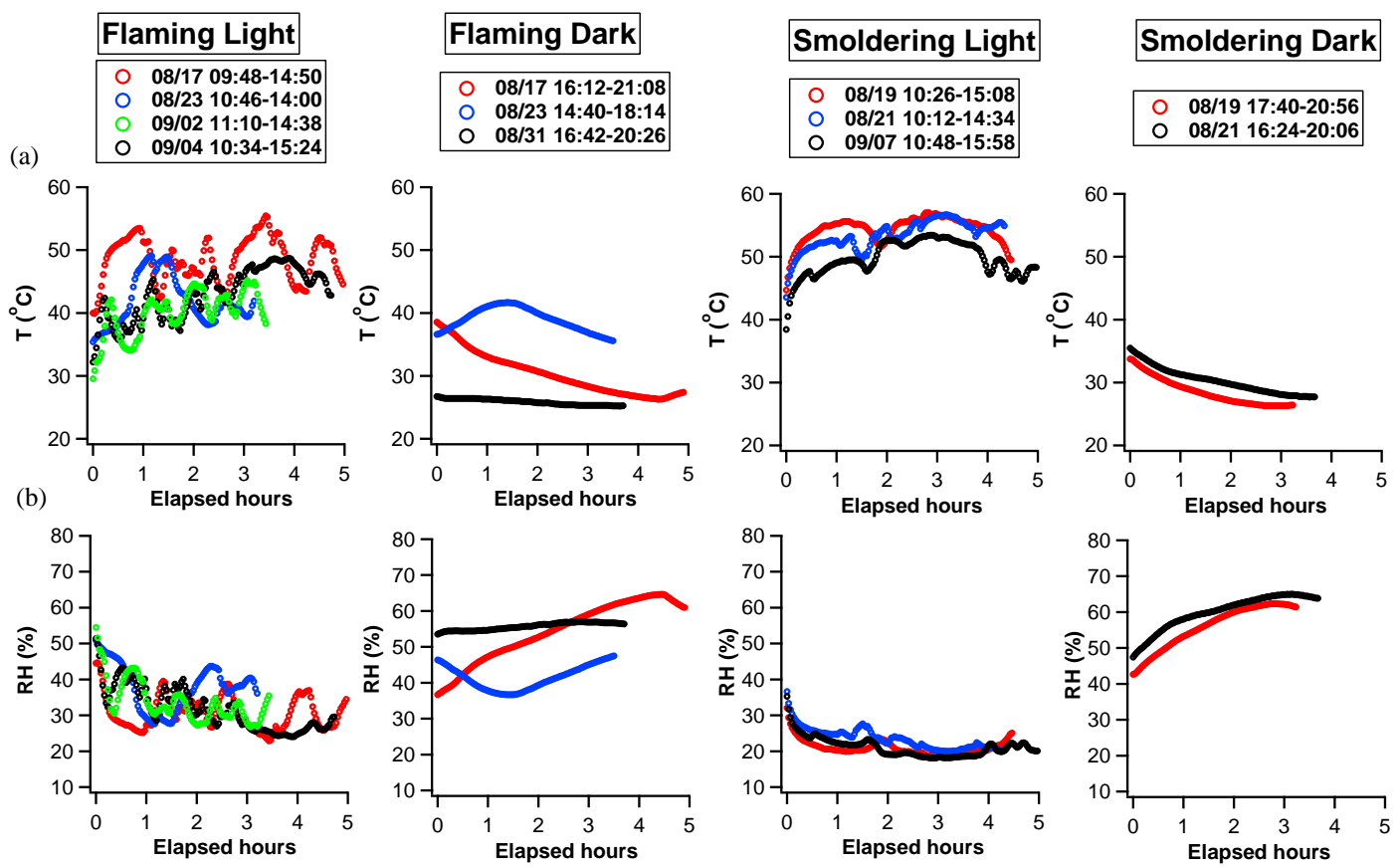

Figure S1. Temporal evolution of (a) temperature and (b) RH in the chamber.

61 

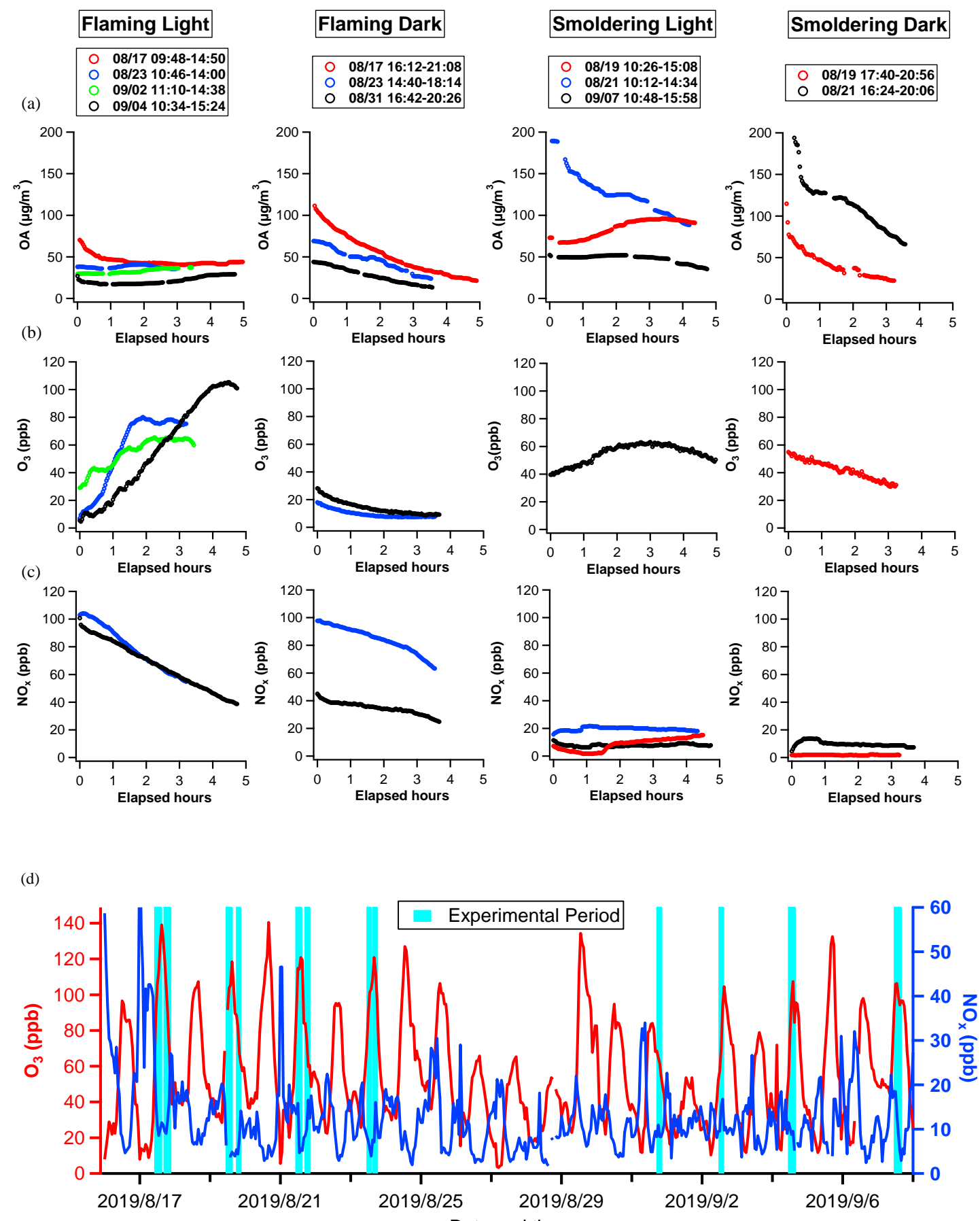

66 Figure S2. Evolution of mass concentration of (a) orgniac aerosol (OA) measured by the AMS, 67 (b) $\mathrm{O}_{3}$, (c) $\mathrm{NO}_{\mathrm{x}}$, (d) anbient $\mathrm{O}_{3}$ and $\mathrm{NO}_{\mathrm{x}}$ with verical bars denoting the periods for individual 68 experiments. 


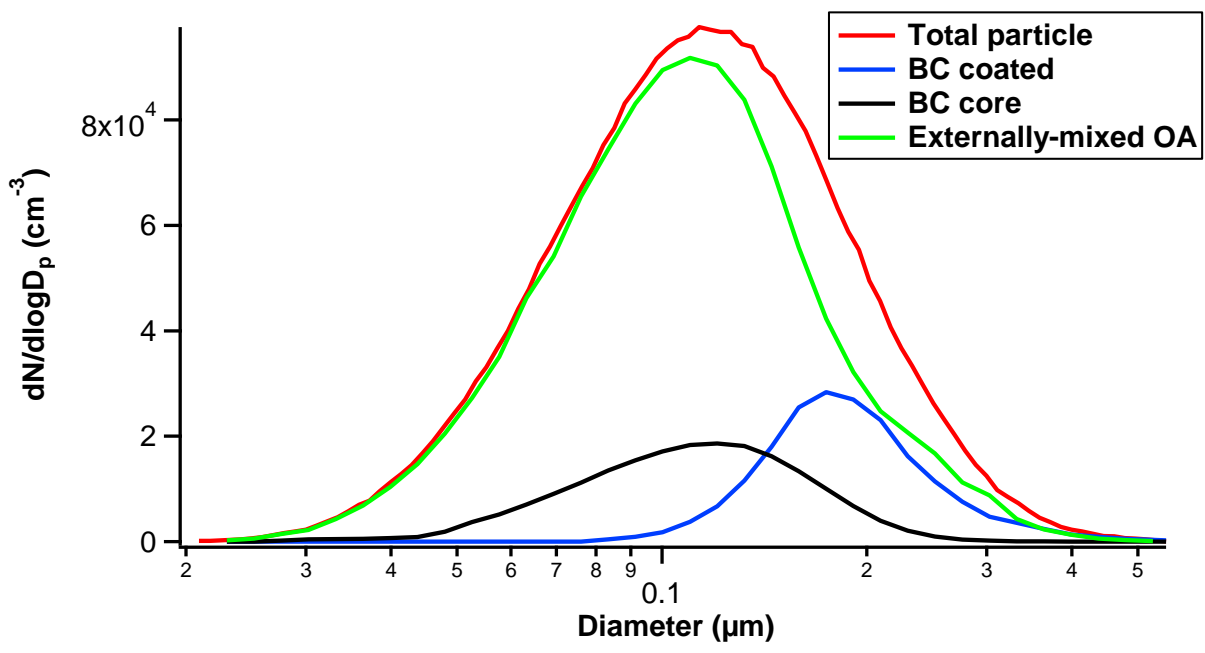

Figure S3. Example of number size distribution of total particle, uncoated (coated) BC and externally-mixed OA, during the flaming light experiment in 0817. 

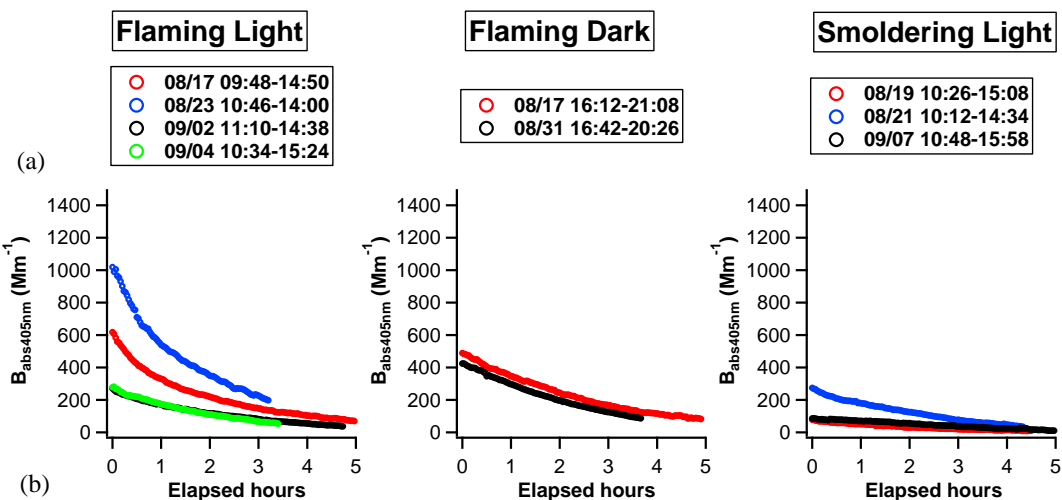

Smoldering Dark
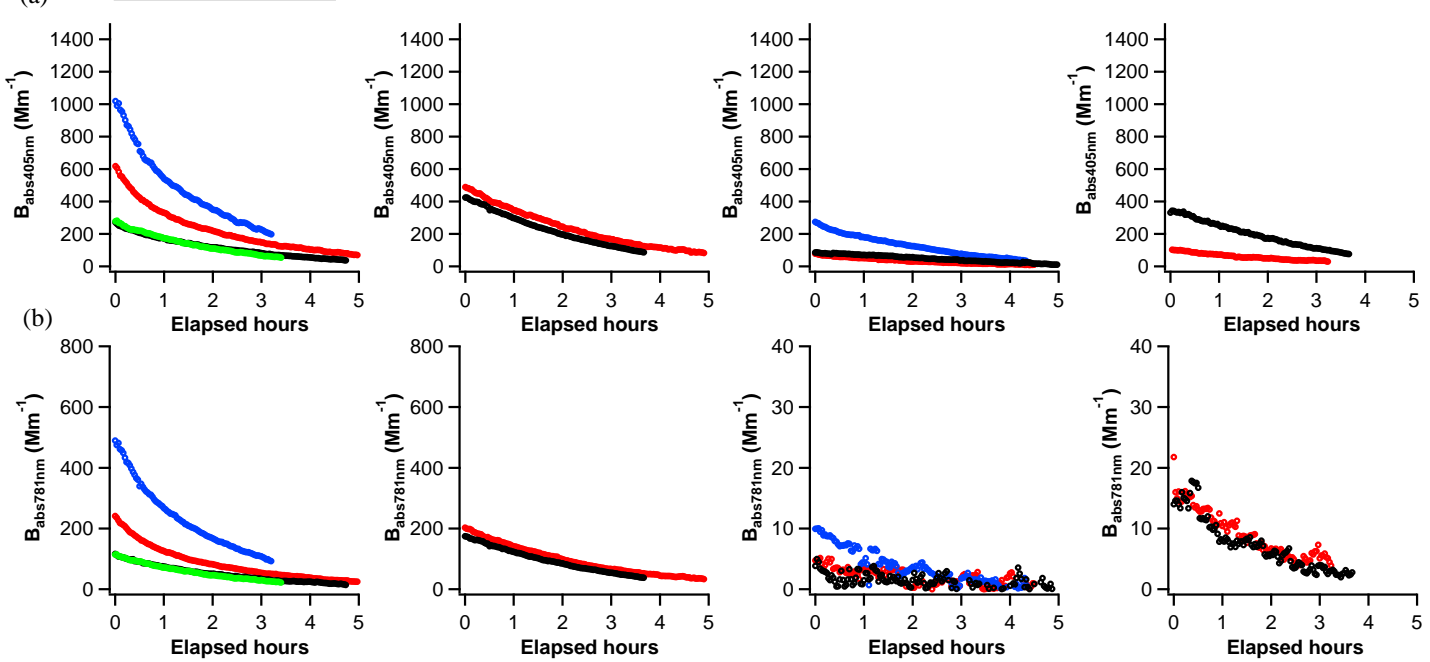

74 Figure S4. Evolution of absorption coefficient measured by the PASS-3 at blue (a) and red (b) 75 for all experiments. 

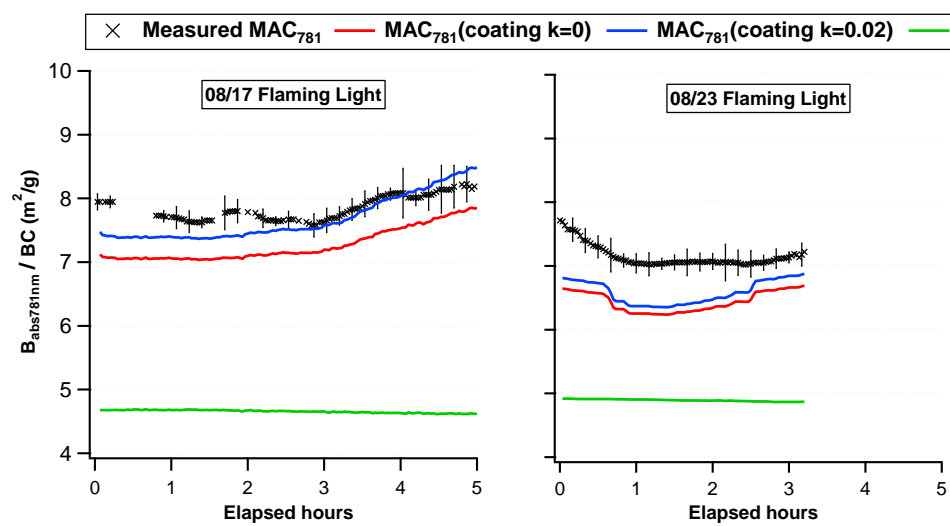

Modelled uncoated $\mathrm{MAC}_{\mathrm{BC}, 781}$
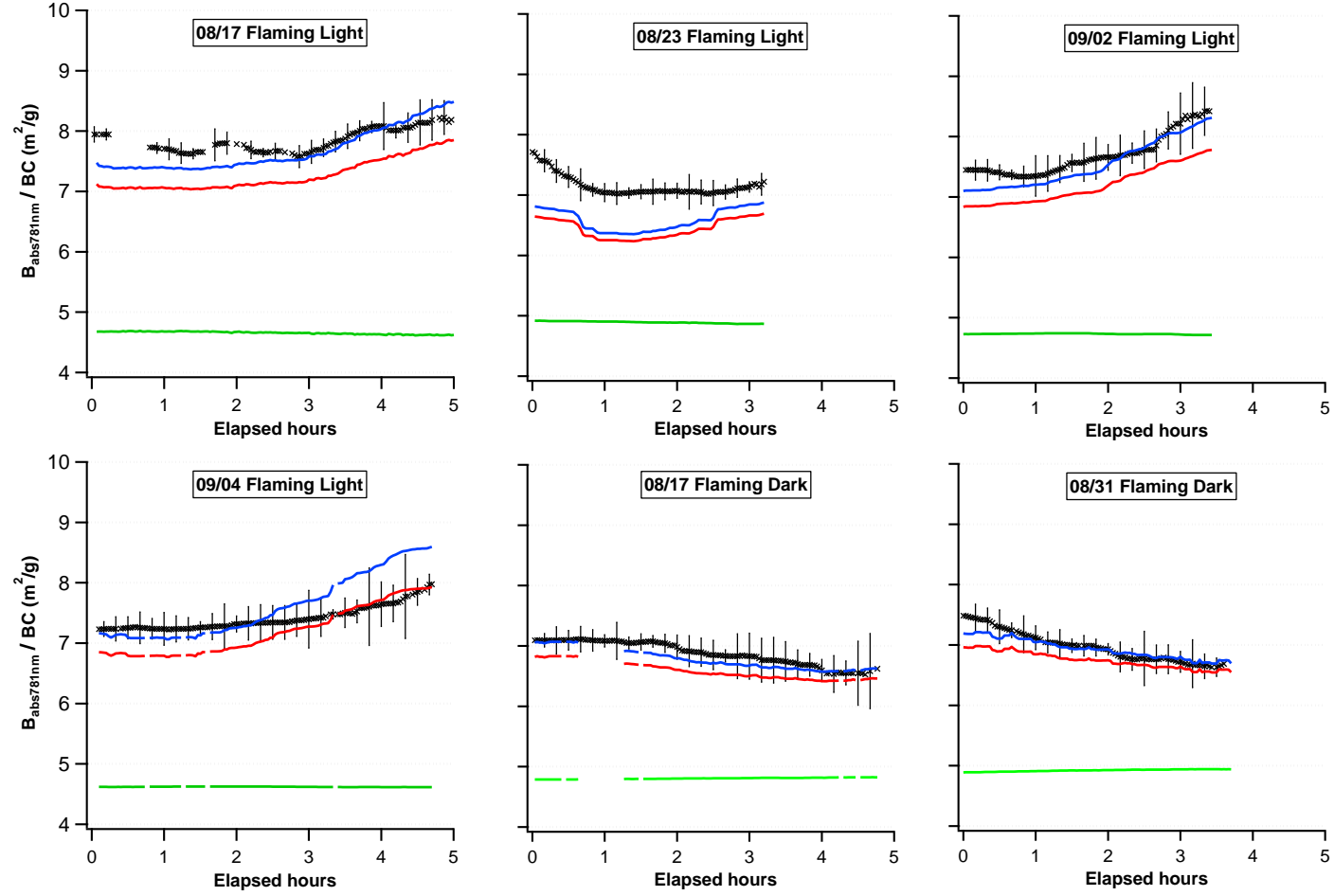

Figure S5. Evolution of absorption coefficient normalized by $\mathrm{rBC}$ mass at $\lambda=781 \mathrm{~nm}$, with error bars showing $\pm \sigma$. Coloured lines show the sensitivity tests of modelling by assuming different imaginary refractive index of $\mathrm{BC}$ coatings at 0 and 0.02 . Green lines show the modelled MAC for uncoated BC. 


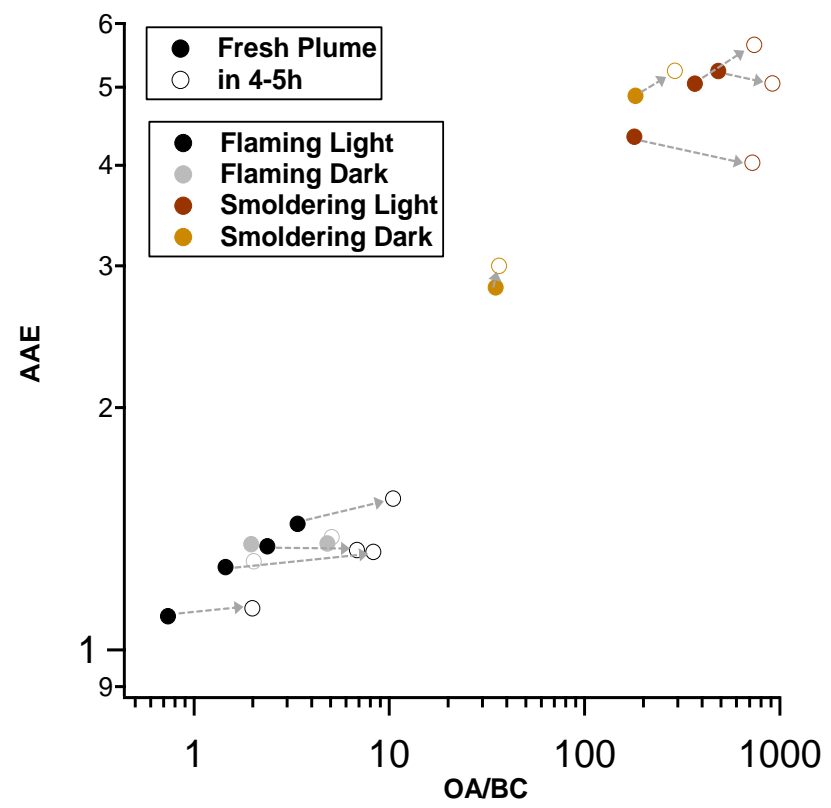

Figure S6. Absorption Ångström Exponent (AAE) as a function of OA/BC for all experiments, showing the mean during the start (solid circle) and the end (open circle) of each experiment. The arrows indicate the properties evolved from the start to the end of each experiment. This can be parameterized as $\mathrm{AAE}=1.6 x+0.64\left(\mathrm{r}^{2}=0.92\right)$, where $x$ is $\log (\mathrm{OA} / \mathrm{BC})$. 


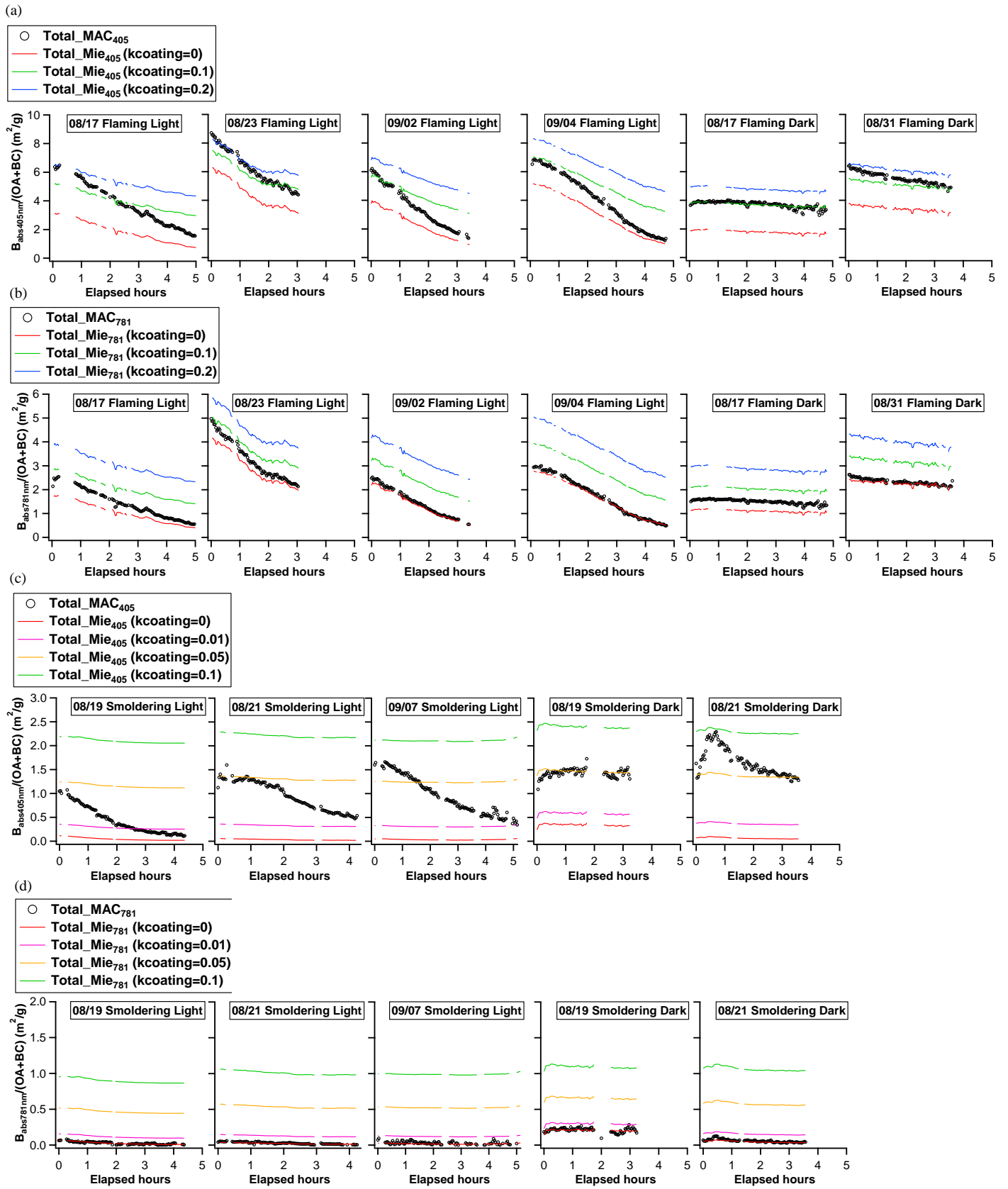

Figure S7. Evolution of absorption efficiency for (a) flaming experiments at $405 \mathrm{~nm}$; (b) flaming experiments at $781 \mathrm{~nm}$; (c) smouldering experiments at $405 \mathrm{~nm}$, and (d) smouldering experiments at $781 \mathrm{~nm}$. The coloured lines show the sensitivity tests of modelling by varying the imaginary refractive index of OA. 

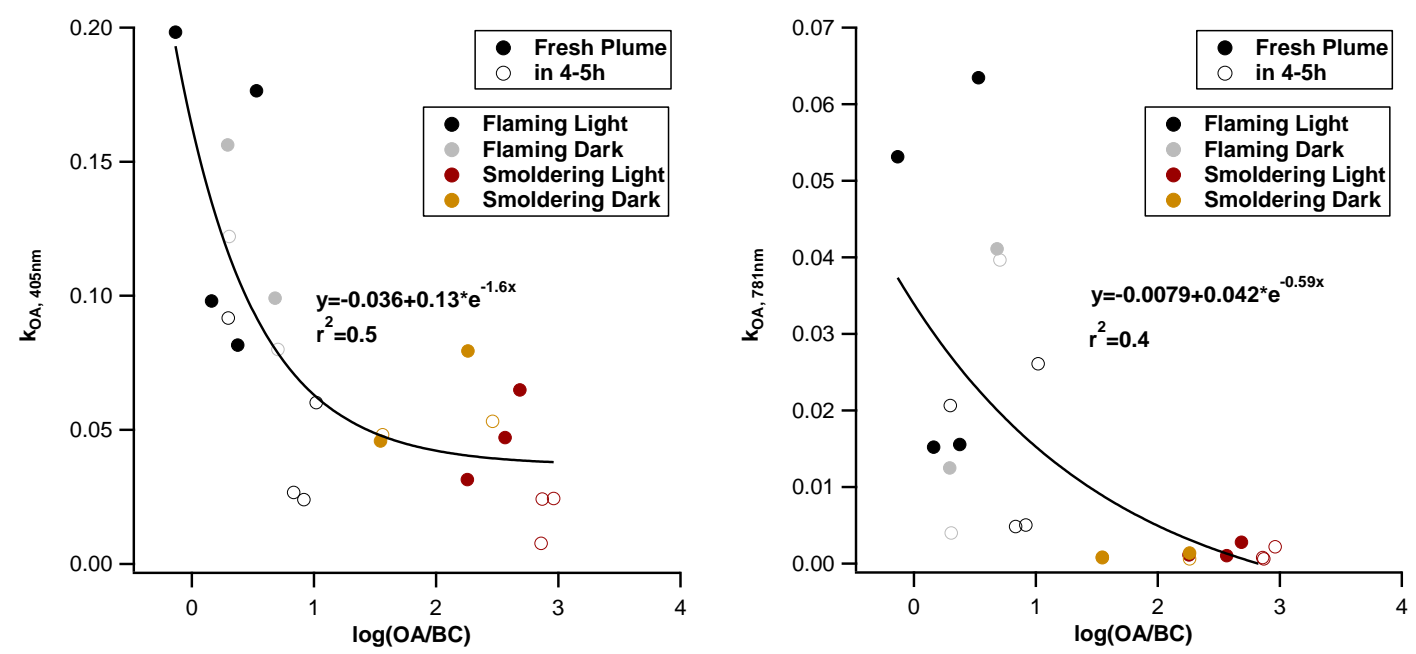

98

99 Figure S8. Optical properties including AAE and $k_{O A}$, as a function of $\log (\mathrm{OA} / \mathrm{BC})$, also 100 showing the least-square fitting functions on each figure.

101 

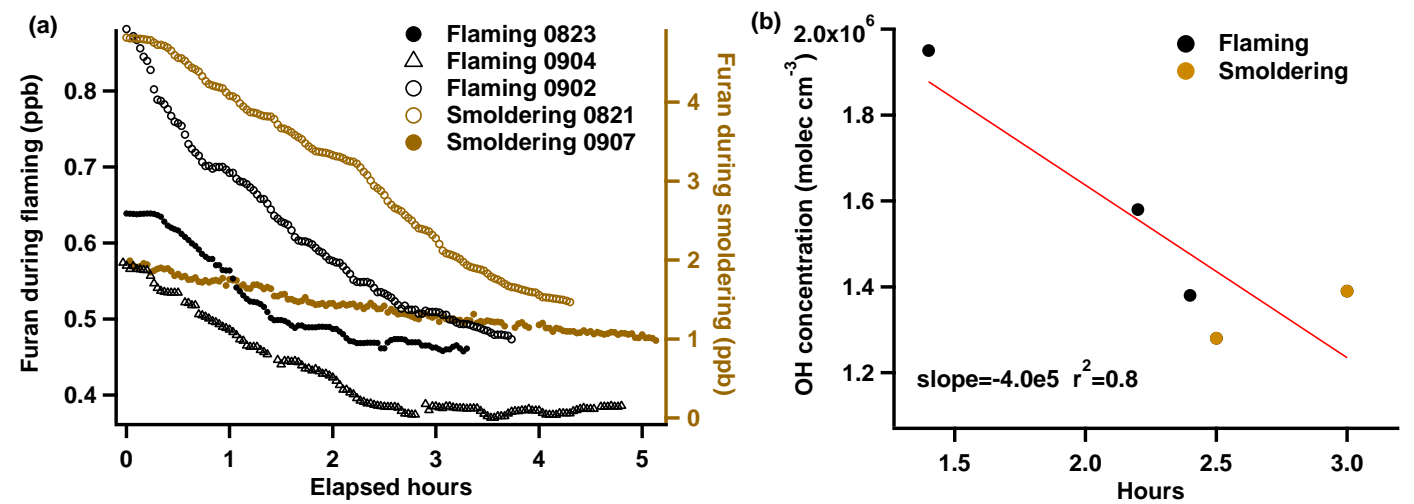

104 Figure S9. (a) Temporal evolution of furan compound in gas phase measured by the PTR-ToF105 MS during light experiments. (b) $\mathrm{OH}$ - concentration in the chamber as a function of half-life of $106 \mathrm{BrC}$. 

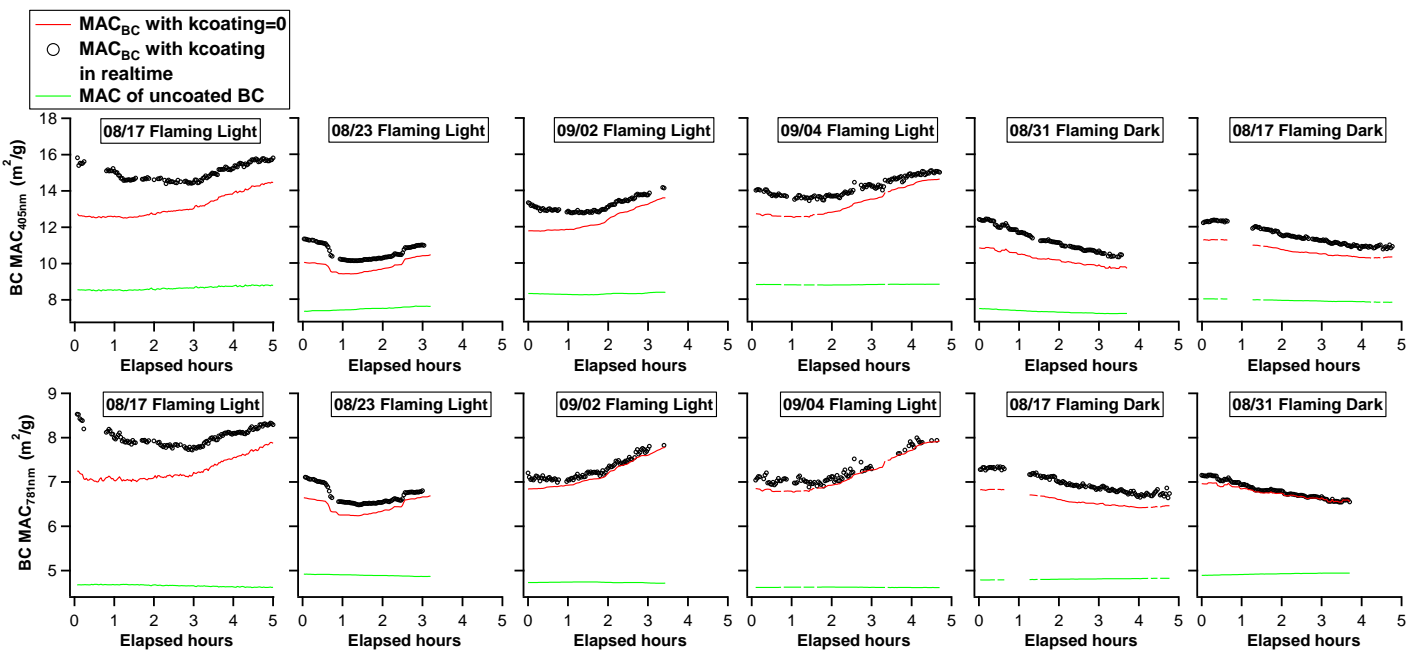

110 Figure S10. Evolution of $\mathrm{MAC}_{\mathrm{BC}}$ assuming non-absorbing coating $\left(k_{\text {coating }}=0\right)$ and $k_{\text {coating }}$ calculated from real-time measurements. Green lines show the modelled MAC for uncoated $\mathrm{BC}$. $\mathrm{MAC}_{\mathrm{BC}}$ during smouldering experiments is not shown due to the very low $\mathrm{BC}$ concentration. 


\section{References}

116 1. Donahue, N. M.; Epstein, S. A.; Pandis, S. N.; Robinson, A. L., A two-dimensional

117 volatility basis set: 1. organic-aerosol mixing thermodynamics. Atmos. Chem. Phys. 2011, 11, 118 (7), 3303-3318.

119 2. Cappa, C. D.; Jimenez, J. L., Quantitative estimates of the volatility of ambient 120 organic aerosol. Atmos. Chem. Phys. 2010, 10, (12), 5409-5424.

$121 \quad 3 . \quad$ May, A. A.; Levin, E. J. T.; Hennigan, C. J.; Riipinen, I.; Lee, T.; Collett Jr., J. L.; 122 Jimenez, J. L.; Kreidenweis, S. M.; Robinson, A. L., Gas-particle partitioning of primary 123 organic aerosol emissions: 3. Biomass burning. J. Geophys. Res. - Atmos. 2013, 118, (19), 124 11,327-11,338.

125 4. Bruns, E. A.; El Haddad, I.; Slowik, J. G.; Kilic, D.; Klein, F.; Baltensperger, U.;

126 Prév?t, A. S. H., Identification of significant precursor gases of secondary organic aerosols 127 from residential wood combustion. Scientific Reports 2016, 6, 27881.

128 5. Sheng, J.; Zhao, D.; Ding, D.; Li, X.; Huang, M.; Gao, Y.; Quan, J.; Zhang, Q.,

129 Characterizing the level, photochemical reactivity, emission, and source contribution of the 130 volatile organic compounds based on PTR-TOF-MS during winter haze period in Beijing, 131 China. Atmos. Res. 2018, 212, 54-63.

$1326 . \quad$ Atkinson, R., Kinetics and mechanisms of the gas-phase reactions of the hydroxyl 133 radical with organic compounds under atmospheric conditions. Chemical Reviews 1986, 86, 134 (1), 69-201. 